\title{
Zinc affects physiology and biosynthesis of medicinal components in Dendrobium nobile Lindl.
}

\author{
Yijun Fan ${ }^{1}$, Ting Jiang ${ }^{1}$, ze chun ${ }^{2}$, gang wang ${ }^{3}$, Suping $\mathrm{Gao}^{1}$, shangrao $\mathrm{pu}^{1}$, and aoxue luo ${ }^{1}$ \\ ${ }^{1}$ Sichuan Agricultural University - Chengdu Campus \\ ${ }^{2}$ Chengdu Institute of Biology \\ ${ }^{3}$ Sichuan Agricultural University College of Forestry
}

October 12, 2020

\begin{abstract}
The growth of Dendrobium nobile is often stressed by zinc. To study the effect of zinc on the growth and biosynthesis of medicinal components, external zinc was regularly sprayed on Dendrobium nobile. The results showed that the net photosynthetic rate, transpiration rate, stomatal conductance, chlorophyll A and B of leaves increased first and then decreased with the increase of zinc concentration. At $400 \mu \mathrm{mol} / \mathrm{L}$, they reached the maximum value, indicating that a certain dose of zinc could promote the photosynthesis of Dendrobium nobile. When the concentration of zinc was $400 \mu \mathrm{mol} / \mathrm{L}$, which could promote the synthesis of SOD, the content of APX and AsA reach the maximum. The content of polysaccharide reached the maximum on the 7th day, the content of polyphenols reached the maximum on the 14th day. This result suggests that exogenous zinc can promote the accumulation of active components in Dendrobium nobile, and when the zinc concentration is $400 \mu$ mol/L, the promoting effect is greatest. While, it was found that the polysaccharide can combine with zinc well to form polysaccharide-zinc chelate, and transform inorganic zinc into organic zinc, which was stored in the form of polysaccharide-Zn in vivo and reduced the damage to Dendrobium nobile by Zn-stress
\end{abstract}

Zinc affects physiology and biosynthesis of medicinal components inDendrobium nobile Lindl. Yijun Fan ${ }^{1}$, Ting Jiang ${ }^{1}$, Ze Chun ${ }^{2}$, Gang Wang ${ }^{3}$, Suping Gao ${ }^{1}$, Shangrao $\mathrm{Pu}^{1}$, Aoxue Luo ${ }^{*}$

1 Department of Landscape Plants, Sichuan Agricultural University, Chengdu 611130, China

2 Chengdu Institute of Biology, Chinese Academy of Sciences, Chengdu 610041, China

3 College of Forest, Sichuan Agricultural University, Chengdu 611130, China

* Corresponding author:aoxueluo@sicau.edu.cn.

Abstract: The growth of Dendrobium nobile is often stressed by zinc. To study the effect of zinc on the growth and biosynthesis of medicinal components, external zinc was regularly sprayed on Dendrobium nobile. The results showed that the net photosynthetic rate, transpiration rate, stomatal conductance, chlorophyll $\mathrm{A}$ and $\mathrm{B}$ of leaves increased first and then decreased with the increase of zinc concentration. At $400 \mu \mathrm{mol} / \mathrm{L}$, they reached the maximum value, indicating that a certain dose of zinc could promote the photosynthesis of Dendrobium nobile. When the concentration of zinc was $400 \mu \mathrm{mol} / \mathrm{L}$, which could promote the synthesis of SOD, the content of APX and AsA reach the maximum. The content of polysaccharide reached the maximum on the 7th day, the content of polyphenols reached the maximum on the 14th day. This result suggests that exogenous zinc can promote the accumulation of active components in Dendrobium nobile, and when the zinc concentration is $400 \mu \mathrm{mol} / \mathrm{L}$, the promoting effect is greatest. While, it was found that the polysaccharide can combine with zinc well to form polysaccharide-zinc chelate, and transform inorganic 
zinc into organic zinc, which was stored in the form of polysaccharide-Zn in vivo and reduced the damage to Dendrobium nobile by Zn-stress

Keywords: Zinc stress; Dendrobium nobile Lindl.; Photosynthesis; Biosynthesis; polysaccharide-Zn.

\section{Introduction}

Zinc, as an essential trace element for plant growth and development, plays an important role in plant physiology and secondary metabolism. Appropriate amount of zinc can promote the growth of plants and enhance their stress resistance. As a special heavy metal ion, zinc can also regulate the secondary metabolism of plants. However, excessive zinc can also affect the normal growth and development of plants, and even cause plant death. Dendrobium nobile is a traditional precious Medicinal Dendrobium, which is one of the Medicinal Dendrobium species clearly recorded in Pharmacopoeia of the people's Republic of China. Dendrobium nobile is mainly distributed in Hejiang county and Mabian County of Sichuan Province and Chishui area of Guizhou Province. However, the contents of $\mathrm{As}, \mathrm{Cu}, \mathrm{Zn}, \mathrm{Cd}, \mathrm{Pb}$ and $\mathrm{Cr}$ in the soils of these areas are relatively high. The highest content of $\mathrm{Zn}$ is $320.58 \mathrm{mg} / \mathrm{g}$, which is 4.32 times of the average soil content of zinc in China( Zhang et al., 2020.). The growth and secondary metabolites of Dendrobium nobile will be affected by the soil with high zinc content.

Plant secondary metabolism is a stress response process to the stress environment ( $\mathrm{Li}$ et al.,2020), and the secondary metabolites produced in this process are necessary substances for plants to resist the stress environment. Studies have shown that the stress of external environment can induce the increase of plant secondary metabolites (Gao et al.,2020) . It is one of the most popular methods to induce plant secondary metabolites by elicitors. As one of the common elicitors, many studies have pointed out that the suitable concentration of heavy metals can effectively induce the biosynthesis of plant secondary metabolites, and excessive concentration will damage the plant organism (Berni et al., 2019) . Some studies show that vinblastine content in catharanthus roseus increases with the increase of exogenous zinc concentration, and the maximum zinc concentration is $150 \mu \mathrm{mol} / \mathrm{L}$ (Ling et al.,2015). Therefore, it can be assumed that zinc, as a heavy metal and essential trace element, has an effect on the secondary metabolites of plants to a certain extent, but with the increase of dose, it may show inhibition effect. The specific mechanism of the effect needs further study.

Some plant polysaccharides can be combined with $\mathrm{Zn}^{2+}$ to become more stable substances, so as to realize the transformation of inorganic zinc into organic zinc, which is more easily absorbed by the human body. Moreover, the polysaccharide with $\mathrm{Zn}^{2+}$ often has higher biological activity, so polysaccharide-zinc has become a research hotspot in recent years. For example, the MFP4P polysaccharide isolated from Mulberry by Wang et al(Wang et al.,2019) has good antioxidant activity and hypoglycemic effect. MFP4P and zinc complex (MFP4P-Zn) have higher antioxidant and hypoglycemic activities than MFP4P at the same concentration. Polysaccharide (P1)-zinc complex (P1-Zn) from Prunella vulgaris could effectively inhibit the proliferation (98.4\% inhibition rate at $500 \mu \mathrm{g} / \mathrm{mL}$ ) of HepG2 cells through induction of apoptosis, evidenced by morphological changes, chromatin condensation and G0/G1 phase cell cycle arrest. (Li et al., 2016). A polysaccharide-zinc (FUP-Zn) complex from Fritillaria ussuriensis exhibited scavenging ability on hydroxyl radicals and superoxide anion radicals. And the effect of polysaccharide-zinc is heavily dependent on the amount of $\mathrm{Zn}$ (Zhang et al.,2020). Polysaccharide chelates of zinc were also found in Pholiota nameko (Lan et al.,2015), Dictyophora indusiate (Liao et al.,2015) and Lentinus edodes (Wang,et al.,2015), which showed strong biological activity in vitro and in vivo.

Recent research shows that Dendrobium nobile has many functions such as anti-aging (Nie et al.,2020), antioxidant activity(Luo et al., 2010), antitumor activity(Wang et al., 2010), immunoregulation(Fan et al.,2020). In the secondary metabolites of Dendrobium nobile, polysaccharides, flavone, alkaloid and polyphenols are abundant, which have high biological activity and important medicinal value. While how does zinc affect the physiological and medicinal composition of Dendrobium nobile?and whether it can chelate with Dendrobium polysaccharide to form zinc polysaccharide products has not been studied. Therefore, this study revealed the effects of exogenous zinc on physiological, medicinal components of Dendrobium nobile and the 
combination of zinc and polysaccharides.

\section{Materials and methods}

\subsection{Plant materials and treatments}

Healthy 1-year-old seedlings with similarly growth rate were used in this research. Dendrobium nobile were cultivated with pine bark as substrate, 20 seedlings as a pot and $75 \%$ shading. After 50 days of planting, the plants were treated by different concentrations of zinc solution every 7 days for 3 moths (the exudate was recycled and irrigated repeatedly until evenly mixed with the cultivated substrate). The test was performed without adding $\mathrm{Zn}^{2+}$ as a control group $(\mathrm{CK})$, and the $\mathrm{Zn}^{2+}$ treatment groups were: T1 group $(50 \mu \mathrm{mol} / \mathrm{L})$, T2 group $(100 \mu \mathrm{mol} / \mathrm{L})$, T3 group $(200 \mu \mathrm{mol} / \mathrm{L})$, T4 group $(400 \mu \mathrm{mol} / \mathrm{L})$, T5 group $(800 \mu \mathrm{mol} / \mathrm{L})$, T6 group $(1000 \mu \mathrm{mol} / \mathrm{L})$, and T7 group $(2000 \mu \mathrm{mol} / \mathrm{L})$. After the end of treatment, the leaves and stems of the Dendrobium nobile with similar growth were selected to test on the $7 \mathrm{th}, 14 \mathrm{th}$, and 21 st days. On the 21st day, the roots ofDendrobium nobile were pulled out, which were washed, then dried in an oven for index determination. Each indicator was tested 3 times.

\subsection{Effects of zinc on photosynthesis of Dendrobium nobile}

The photosynthetic parameters were measured using a photosynthetic apparatus (Li-6400). The net photosynthetic rate $(\mathrm{Pn})$, transpiration rate $(\mathrm{Tr})$, stomatal conductance $(\mathrm{Gs})$ of the fully expanded leaves were measured and their variation laws will be calculated. The contents of chlorophyll a (Chl.A) and chlorophyll b (Chl.B) of the leaves from Dendrobium nobile were determined according to the method of Tehseen et al. (Asghar et al., 2016). After crushed, $0.1 \mathrm{~g}$ fresh leaves were extracted with $5 \mathrm{~mL}$ of $80 \%$ acetone in the dark for $24 \mathrm{~h}$. The extracts were combined and made up to $25 \mathrm{~mL} .80 \%$ acetone was used as a control, and the colorimetric was tested at spectrophotometers at $663 \mathrm{~nm}$ and $645 \mathrm{~nm}$, and the chlorophyll content were calculated.

\subsection{Effects of zinc on the antioxidant system ofDendrobium nobile}

The content of hydrogen peroxide $\left(\mathrm{H}_{2} \mathrm{O}_{2}\right)$ was determined according to the method of Park et al. (Park et al.,2016). The content of superoxide anion $\left(\mathrm{O}_{2}{ }^{-}\right)$was determined by using the method of Chen et al.( Chen et al.,2019). The SOD activity was determined by using nitroblue tetrazolium (NBT) photochemical reduction method(Milosevic et al., 1996). Ascorbate peroxidase (APX) activity was determined by ascorbate oxidation(Carolina et al., 2017). The content of AsA was assayed according to Kunpatee et al. (Kunpatee et al.,2020) with $\mathrm{mg} \cdot \mathrm{g}^{-1} \mathrm{FW}$ as the unit of measurement. The content of reduced glutathione (GSH) was determined by mercapto reagent(DTNB) according to the method of Nagalakshmi (Nagalakshmi et al., 2001).

\subsection{Effects of zinc on the medicinal components ofDendrobium nobile}

\subsubsection{Determination of polysaccharide content}

The polysaccharide content was determined by the modified phenol-sulfuric acid method (Luo et al., 2010). Dry powder ofDendrobium nobile $(0.5 \mathrm{~g})$ was placed in a $100 \mathrm{~mL}$ round bottom flask, added $50 \mathrm{~mL} 80 \%$ ethanol heated at 80 reflux for $1 \mathrm{~h}$. Then the solution was filtered and the filtrate was discarded. Next the filter residue was placed in the round bottom flask again. $50 \mathrm{~mL}$ of distilled water was added, and the mixture was heated to reflux at 100 for 2 hours, and the filtrate was taken, and the volume was adjusted to $50 \mathrm{~mL}$ to obtain a polysaccharide extract. The polysaccharide content was determined by the phenol-sulfuric acid method. The standard curve is made with glucose.

\subsubsection{Determination of polyphenol content}

The content of polyphenol was determined by a Folin phenol reagent according to the method of Liu et al.( Liu et al., 2019). Weigh accurately $0.1 \mathrm{~g}$ of stem sample, placed in a $100 \mathrm{~mL}$ Erlenmeyer flask, add 50mL of $70 \%$ ethanol, shake for 4 hours, filter, and the filtrate was dilute to $100 \mathrm{~mL}$. Accurately measure $1 \mathrm{~mL}$ of the extract, add $0.3 \mathrm{~mL}$ of $\mathrm{FC}$ reagent, and mix for $5 \mathrm{~min}$. Add $1.5 \mathrm{~mL}$ of saturated sodium carbonate solution, 
add water to a volume of $10 \mathrm{~mL}$, shake for $30 \mathrm{~min}$ in a 30 water-bath. Then, the absorbance was measured at $760 \mathrm{~nm}$. The standard curve is made with gallic acid.

\subsubsection{Determination of total flavonoids}

The content of total flavonoids was determined according to the method of Quy et al. (Quy et al., 2014). $0.1 \mathrm{~g}$ of stem sample was placed in a $100 \mathrm{~mL}$ round bottom flask, add $50 \mathrm{~mL}$ of $75 \%$ ethanol and reflux at 80 for $2 \mathrm{~h}$. After that, the extracting solution was filted, and, the filtrate was collected. The filtrate was dilute to $50 \mathrm{~mL}$ with $75 \%$ ethanol. Take $1 \mathrm{~mL}$ of the filtrate in a $10 \mathrm{~mL}$ volumetric flask, add $4 \mathrm{~mL}$ of $50 \%$ ethanol solution, add $0.3 \mathrm{~mL}$ of $5 \%$ sodium nitrite solution, shake well, place for $6 \mathrm{~min}$. Next add $0.3 \mathrm{~mL}$ of $10 \%$ aluminum nitrate solution in it, shake well, then place for $6 \mathrm{~min}$, add $4 \mathrm{~mL}$ of $1 \mathrm{~mol} / \mathrm{L}$ sodium hydroxide solution was diluted to $50 \%$ ethanol, and shaken for $15 \mathrm{~min}$. The absorbance at $510 \mathrm{~nm}$ was measured. The standard curve was made with rutin reference solution.

\subsection{Determination of polysaccharide- zinc in Dendrobium nobile}

A certain amount of polysaccharide samples was put into microwave digestion tube, and $1 \mathrm{~mL}$ hydrofluoric acid was added to $5 \mathrm{~mL}$ concentrated nitric acid. Then put the tube in ventilation room for overnight. Fixed volume to $50 \mathrm{~mL}$ after complete digestion. Determination of zinc in each component by Flame Atomic Absorption Spectrometry(Altair et al., 2018).

\subsection{Data statistics and analysis}

All data were statistically analyzed using SPSS 23.0 software, one-way ANOVA and least significant difference test (LSD), and Excel 2010 tabulation. The significance level was set to $a=0.05$.

1. Results

2. Effects of exogenous zinc on photosynthesis of Dendrobium nobile

3.1.1 Effects of different concentrations of zinc on net photosynthetic rate $\left(P_{n}\right)$ and transpiration rate $\left(\mathrm{T}_{\mathrm{r}}\right)$ of Dendrobium nobile

Figure 1a shows that the net photosynthetic rate varies with the time of zinc treatment and zinc concentration. Compared with the control group, the net photosynthetic rate of the treatment group with zinc concentration less than $800 \mu \mathrm{mol} / \mathrm{L}$ was significantly higher than that of the control group. When the zinc concentration was less than $400 \mu \mathrm{mol} / \mathrm{L}$, the net photosynthetic rate increased slowly with the prolongation of zinc treatment time, but there was no significant difference between different treatment days. At the same time, when the zinc concentration is less than 400, the net photosynthetic rate increases with the increase of zinc concentration. When the zinc concentration was $400 \mu \mathrm{mol} / \mathrm{L}$, it reached the maximum value, and there was significant difference compared with the control group.

Figure $1 \mathrm{~b}$ shows that the transpiration rate varies with the time of zinc treatment and zinc concentration. Compared with the control group, the transpiration rate of all treatment groups with zinc concentration less than $400 \mu \mathrm{mol} / \mathrm{L}$ was significantly higher than that of the control group, and increased significantly with the increase of zinc concentration. At the same time, we found that when the zinc concentration was between $200 \mu \mathrm{mol} / \mathrm{L}$ and $400 \mu \mathrm{mol} / \mathrm{L}$, the transpiration rate increased significantly with the increase of zinc treatment time. However, when the concentration of zinc was more than $400 \mu \mathrm{mol} / \mathrm{L}$, the transpiration rate decreased significantly with the increase of zinc concentration. When the zinc concentration was 400 $\mu \mathrm{mol} / \mathrm{L}$ and the treatment time was 21 days, the transpiration rate reached the maximum value, and there was significant difference compared with the control group.

Fig 1.

\subsubsection{Effects of different concentrations of zinc on $\mathrm{G}_{\mathrm{s}}$ and $\mathrm{Ci}$} of Dendrobium nobile 
Figure 1c shows that the stomatal conductance $\left(\mathrm{G}_{\mathrm{s}}\right)$ changes with the time of zinc treatment and zinc concentration. Compared with the control group, the $\mathrm{G}_{\mathrm{s}}$ concentration of all treatment groups with zinc concentration less than $400 \mu \mathrm{mol} / \mathrm{L}$ was significantly higher than that of the control group, and increased significantly with the increase of zinc concentration, and increased significantly with the extension of zinc treatment time. However, when the zinc concentration is more than $400 \mu \mathrm{mol} / \mathrm{L}$, the $\mathrm{G}_{\mathrm{s}}$ concentration decreases significantly with the increase of zinc concentration. When the zinc concentration was $400 \mu \mathrm{mol} / \mathrm{L}$ and the treatment time was 21 days, the $\mathrm{G}_{\mathrm{s}}$ concentration reached the maximum value, and there was significant difference compared with the control group.

It can be seen from Figure 1d that the carbon dioxide concentration $(\mathrm{Ci})$ changes with the time of zinc treatment and zinc concentration. Compared with the control group, the carbon dioxide concentration of all the treatment groups with zinc concentration less than $400 \mu \mathrm{mol} / \mathrm{L}$ was significantly lower than that of the control group, and decreased slowly with the increase of zinc concentration. But when the zinc concentration is $400 \mu \mathrm{mol} / \mathrm{L}$, the $\mathrm{Ci}$ concentration reaches the minimum value, and compared with the control group, there is a significant difference. But at the same zinc concentration, with the extension of zinc treatment time, the $\mathrm{Ci}$ decreased, but there was no significant difference. When the zinc concentration is more than $400 \mu \mathrm{mol} / \mathrm{L}$, the $\mathrm{Ci}$ concentration increases gradually with the increase of zinc concentration and treatment time. When the zinc concentration was $2000 \mu \mathrm{mol} / \mathrm{L}$ and the treatment time was 21 days, the Ci concentration reached the maximum value, and there was significant difference compared with the control group.

\subsubsection{Effects of different concentrations of zinc on efficiency of water application (WUE) of leaves from Dendrobium nobile}

It can be seen from Table 1 that there is no direct correlation between water use and zinc concentration in each zinc treatment group. However, at the same zinc treatment concentration, with the extension of zinc treatment time, the water use degree decreased gradually. Compared with that of 7 days, the water use degree of 14 days treatment decreased significantly. However, compared with the water use degree of 14 days, the water use degree of 21 days decreased slightly.

Table 1

\subsubsection{Effects of different concentrations of Zinc on chlorophyll A and B contents of the leaves from Dendrobium nobile}

Table 2 shows that in the same zinc treatment time, the content of chlorophyll A and B increases first and then decreases with the increase of zinc concentration. When the zinc concentration was $400 \mu \mathrm{mol} / \mathrm{L}$, it reached the maximum value, which was significantly different from the control group. When zinc concentration was more than $400 \mu \mathrm{mol} / \mathrm{L}$, the content of chlorophyll A and chlorophyll B began to decrease. But at the same zinc concentration, when the treatment time was 14 days, compared with 7 days, chlorophyll A and B increased significantly. However, when the treatment time was 21 days, compared with 14 days, the content of chlorophyll AB increased, but the increase was not significant.

Table 2

\subsection{Effects of different concentrations of exogenous Zinc on antioxidant system of Dendrobium nobile}

\subsubsection{Effects of different concentrations of Zinc on $\mathrm{H}_{2} \mathrm{O}_{2}$ and superoxide anion in leaves ofDendrobium nobile}

With the increase of zinc treatment time, the content of $\mathrm{H}_{2} \mathrm{O}_{2}$ in each group is also increasing. The results showed that the longer zinc treatment time, the greater the stimulation to Dendrobium nobile, and the more $\mathrm{H}_{2} \mathrm{O}_{2}$ produced. On the 21st day, from the zinc concentration of $200 \mu \mathrm{mol} / \mathrm{L}$, compared with CK group, the content of $\mathrm{H}_{2} \mathrm{O}_{2}$ increased significantly, but when the zinc concentration was between $400 \mu \mathrm{mol} / \mathrm{L}-1000$ $\mu \mathrm{mol} / \mathrm{L}$, the content of $\mathrm{H}_{2} \mathrm{O}_{2}$ in each zinc treatment group increased slowly, there was no significant difference between the groups. When zinc concentration increased to $2000 \mu \mathrm{mol} / \mathrm{L}$, the content of $\mathrm{H}_{2} \mathrm{O}_{2}$ increased 
significantly. The results showed that the zinc concentration of $2000 \mu \mathrm{mol} / \mathrm{L}$ and long-term treatment could make Dendrobium nobile produce more $\mathrm{H}_{2} \mathrm{O}_{2}$.

Fig. 2

With the increase of zinc treatment time and zinc concentration, the $\mathrm{O}_{2}{ }^{-}$content of each group is also increasing. The results showed that the longer zinc treatment time, the higher concentration, the greater stimulation to Dendrobium nobile, and the more $\mathrm{O}_{2}{ }^{-}$produced. At 14 days of treatment, when the zinc concentration was more than $800 \mu \mathrm{mol} / \mathrm{L}$, the content of $\mathrm{O}_{2}{ }^{-}$increased significantly compared with the low concentration zinc treatment group. But there was no significant difference between T5 $(800 \mu \mathrm{mol} / \mathrm{L})$ group and T6 $(1000 \mu \mathrm{mol} / \mathrm{L})$ group. When the zinc concentration is $2000 \mu \mathrm{mol} / \mathrm{L}$, it has a significant increase compared with $1000 \mu \mathrm{mol} / \mathrm{L}$. The results showed that zinc concentration of $2000 \mu \mathrm{mol} / \mathrm{L}$ and longtime treatment could make Dendrobium nobile produce more $\mathrm{O}_{2}{ }^{-}$.

3.2.2Effect of different concentrations of zinc on the content of soluble sugar, proline and soluble protein in Dendrobium nobile leaves

It can be seen from Figure3a, on the 7th and 14th day, when the zinc concentration was $2000 \mu \mathrm{mol} / \mathrm{L}$, the soluble sugar content reached the maximum. However, on the 21st day, when the zinc concentration was $400 \mu \mathrm{mol} / \mathrm{L}$, the soluble sugar content reached the maximum. The results showed that zinc had a greater effect on the production of soluble sugar with the increase of zinc treatment time, and it could stimulate the production of more soluble sugar even at a lower concentration.

As shown as Figure3b, within 14 days after zinc treatment, the soluble protein of each group changed in varying degrees, but there was no regularity. After 21 days of zinc treatment, there was a regular trend of change, first increased and then decreased. When the zinc concentration was $800 \mu \mathrm{mol} / \mathrm{L}$, the soluble protein content was the most, and there was a significant difference compared with the control group. This result shows that zinc treatment for a long time could stimulate the secretion of soluble protein.

Fig. 3

\subsubsection{Effects of different concentrations of exogenous Zinc on SOD and CAT activities in Dendrobium nobile}

It can be seen from Table 3 that when the zinc concentration is less than $200 \mu \mathrm{mol} / \mathrm{L}$, the SOD content in Dendrobium nobile leaves gradually increases with the increase of zinc treatment time. When the zinc concentration is more than $400 \mu \mathrm{mol} / \mathrm{L}$, the content of SOD decreases with the increase of zinc concentration. The results showed that the stimulation of low zinc concentration on Dendrobium nobile could promote the synthesis of SOD, which could eliminate the free radicals produced by stress. When zinc concentration is high, no more antioxidant enzymes will be produced, which will lead to more free radicals accumulation in Dendrobium nobile .

\section{Table 3}

It can also be seen from Table 3 that the cat content of all groups increased with the prolongation of zinc treatment time and the increase of zinc concentration. But the increase of cat in zinc treatment group was significantly higher than that in control group. The results showed that with the increase of zinc concentration and zinc treatment time, the cat content of Dendrobium nobile increased significantly, which may be due to the large amount of hydrogen peroxide produced by Dendrobium nobile under the stimulation of zinc.

3.2.4 Effects of different concentrations of exogenous Zinc on the contents of APX,AsA and GSH activities in leaves ofDendrobium nobile

As can be seen from Figure 4a, the content of APX increases with the increase of zinc treatment concentration. At 14 days of treatment, when the zinc concentration was less than $100 \mu \mathrm{mol} / \mathrm{L}$, there was no significant change in APX content compared with the control group. However, with the prolongation of the treatment 
time, when the zinc concentration is greater than $100 \mu \mathrm{mol} / \mathrm{L}$, the APX content of the treatment group is significantly higher than that of the control group. At the same time, it can be seen from the figure that when the zinc concentration is in the range of 200-1000 $\mu \mathrm{mol} / \mathrm{L}$, after 14 days of zinc treatment, it is significantly increased compared with the control. The peak value of APX appeared at zinc concentration of $400 \mu \mathrm{mol} / \mathrm{L}$ and treatment time of 14 days.

Fig. 4

As can be seen from Figure 4b, AsA content increases first and then decreases with the increase of zinc concentration. At 14 days of treatment, when the zinc concentration was less than $400 \mu \mathrm{mol} / \mathrm{L}$, AsA content increased with the increase of zinc concentration compared with the control group, and reached the maximum value at the zinc concentration of $400 \mu \mathrm{mol} / \mathrm{L}$. When zinc concentration is more than $400 \mu \mathrm{mol} / \mathrm{L}$, AsA content decreases with the increase of zinc concentration. After 14 days of zinc treatment, when the zinc concentration was $400 \mu \mathrm{mol} / \mathrm{L}$, AsA content showed a peak value, and there was a significant difference between the two groups.

It can be seen from Figure 4c that the content of GSH increases first and then decreases with the increase of zinc concentration. When zinc concentration is less than $400 \mu \mathrm{mol} / \mathrm{L}$, GSH content increases with the increase of zinc treatment time and zinc concentration. When the zinc concentration is $800 \mu \mathrm{mol} / \mathrm{L}$, the GSH content has a peak value, and there is a significant difference for the photographic ratio.

\subsection{Effects of different concentrations of exogenous Zinc on medicinal components of Dendro- bium nobile.}

It can be seen from Figure 5 that the total polysaccharide content ofDendrobium nobile varies with the zinc treatment concentration. When the zinc concentration is less than $400 \mu \mathrm{mol} / \mathrm{L}$, the polysaccharide content gradually increases with the increase of zinc concentration. When the zinc concentration was $400 \mu \mathrm{mol} / \mathrm{L}$, it was significantly higher than the control, and when the zinc treatment time was 7 days, the content of polysaccharide reached the maximum. When the zinc concentration is more than $400 \mu \mathrm{mol} / \mathrm{L}$, the content of polysaccharide decreases with the increase of zinc concentration.

Fig.5

It can be seen from Figure 5 that the total polyphenol content ofDendrobium nobile varies with the zinc treatment concentration. When the zinc concentration is less than $400 \mu \mathrm{mol} / \mathrm{L}$, the polyphenol content gradually increases with the increase of zinc concentration. When the zinc concentration is $400 \mu \mathrm{mol} / \mathrm{L}$, compared with the control, it is significantly higher than the control. When the zinc treatment time is 14 days, the content of polyphenols reaches the maximum. When the concentration of zinc was more than $400 \mu \mathrm{mol} / \mathrm{L}$, the content of polyphenols decreased with the increase of zinc concentration, but it was still significantly higher than the control group.

It can be seen from Figure 5 that the flavonoid content ofDendrobium nobile varies with the zinc treatment concentration. When the zinc concentration is less than $400 \mu \mathrm{mol} / \mathrm{L}$, the flavonoid content gradually increases with the increase of zinc concentration. When the zinc concentration was $400 \mu \mathrm{mol} / \mathrm{L}$, it was significantly higher than the control, and when the zinc treatment time was 21 days, the content of flavonoids reached the maximum. When the zinc concentration is more than $400 \mu \mathrm{mol} / \mathrm{L}$, the content of polysaccharide decreases with the increase of zinc concentration. When the zinc treatment time was less than 21 days, it was still significantly higher than the control group. However, when the zinc treatment time was more than 21 days, the content of flavonoids decreased.

\subsection{Effect of exogenous zinc on the synthesis of zinc polysaccharide from Dendrobium nobile}

It can be seen from Figure 6 that zinc polysaccharide varied with zinc concentration and zinc treatment time. When the zinc concentration was less than $800 \mu \mathrm{mol} / \mathrm{L}$, the content of zinc polysaccharide increased with the increase of zinc concentration. With the extension of zinc treatment time, the content of zinc polysaccharide in each group decreased gradually. Therefore, when the zinc concentration is $800 \mu \mathrm{mol} / \mathrm{L}$ 
and the treatment time is 7 days, the content of zinc polysaccharide reaches the maximum value, and there is significant difference compared with the control.

Fig.6

1. Discussion

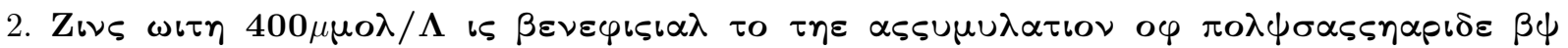
$\pi \rho 0 \mu о \tau \iota \nu \gamma \pi \eta \sigma \tau o \sigma \psi \nu \tau \eta \varepsilon \sigma \iota s$

Zinc is a component of many structural substances in plants, and also an activator of many enzymes, which plays an important role in plant photosynthesis. In this study, it was found that the photosynthesis of leaves could be affected by the application of zinc. With the increase of exogenous zinc concentration, the photosynthesis of Dendrobium nobile was promoted by zinc concentration below $400 \mu \mathrm{mol} / \mathrm{L}$. The net photosynthetic rate and stomatal conductance, and chlorophyll a and $\mathrm{b}$ reached the maximum when the concentration of zinc was $400 \mu \mathrm{mol} / \mathrm{L}$. The water use efficiency of leaves decreased gradually with the increase of concentration and treatment time. The results also showed that proper concentration of zinc could help Dendrobium nobile produce chlorophyll and promote plant photosynthesis. It may be that exogenous application of zinc increased the zinc content in chloroplasts, inhibited the activity of RNA hydrolase, promoted the production of RNA, and then promoted the synthesis of chloroplast protein, increased the content of chlorophyll a and chlorophyll b. The increase of photosynthesis increased the synthesis of soluble sugar in Dendrobium. The results showed that the soluble sugar content reached the maximum at the concentration of zinc with $400 \mu \mathrm{mol} / \mathrm{L}$ on the 21st day. Polysaccharide is a kind of complex and huge carbohydrate which is formed by condensation and dehydration of many soluble sugar (monosaccharide) molecules. Therefore, soluble monosaccharide molecules are the raw materials for the biosynthesis of polysaccharides, and the concentration of $400 \mu \mathrm{mol} / \mathrm{L}$ zinc can promote the photosynthesis of Dendrobium nobile and increase the synthesis of soluble monosaccharide, which providing the necessary raw materials for the synthesis of Dendrobium nobile polysaccharides.

\subsection{Low concentration of zinc can improve the stress resistance ofDendrobium nobile}

When plants are in adversity environment, hydrogen peroxide and free radical ions will produce toxicity to plants. However, plants have resistance mechanism to adversity. In order to avoid injury, plants can eliminate the damage caused by reactive oxygen species by adjusting themselves, such as improving the activity of antioxidant enzymes and increasing the content of antioxidant substances. This study showed that when exogenous zinc was applied to Dendrobium nobile, the production rate of hydrogen peroxide and superoxide radicals in the leaves of Dendrobium nobile increased gradually with the increase of zinc treatment concentration, indicating that exogenous zinc had different degrees of stress on Dendrobium nobile, and high zinc stress was the most obvious.

SOD is an important enzyme for scavenging reactive oxygen species in plants. It is responsible for transforming superoxide anion radicals into hydrogen peroxide. In this study, SOD activity increased first and then decreased with the increase of zinc concentration, indicating thatDendrobium nobile can resist external stress through self-regulation within a certain concentration range. But when zinc concentration was more than $1000 \mu \mathrm{mol} / \mathrm{L}$, SOD activity was lower than that of control.

Ascorbic acid (AsA) and glutathione (GSH), as important non-enzymatic antioxidants in plants, can directly act and scavenge reactive oxygen species. GSH increased in response to biological stresses such as reactive oxygen species accumulation. Our study shows that with the increase of zinc concentration, GSH in Dendrobium nobileincreases first and then decreases. The results showed that high concentration of zinc increased the oxidative stress of Dendrobium nobile. AsA can scavenge many kinds of reactive oxygen radicals such as hydrogen peroxide directly or indirectly through the AsA-GSH cycle. After applying exogenous zinc, AsA first increases and then decreases with increasing concentration. APX is an important antioxidant enzyme in plants. Its activity determines the role of AsA-GSH cycle in stress resistance physiology. The results show that APX activity increases first and then decreases with the increase of zinc concentration. Therefore, the activities of antioxidant enzymes were also destroyed when zinc concentration was too high. 
In conclusion, low concentration of zinc can improve the stress resistance of Dendrobium nobile, but high concentration of zinc can cause the degree of peroxidation of Dendrobium nobile, and even affect its normal growth.

\subsection{Effect of zinc on the accumulation of polyphenols and flavonoids inDendrobium nobile.}

Polyphenols and flavonoids are also main active ingredients in Dendrobium nobile. The results showed that zinc had a low promoting and high inhibiting effect on the polyphenols and flavonoids contents of Dendrobium nobile. This may be because zinc, as a heavy metal ion, is a kind of inducer, which can induce and stimulate plants to produce secondary metabolites, which is similar to the research of Jin (Jin et al., 2015), which found that exogenous zinc can promote the production of vinblastine in Changchun flower. The results showed that after the application of zinc in medicinal plants, it was beneficial to the accumulation of medicinal components and increase the medicinal value of Dendrobium nobile.

\subsection{Dendrobium nobile can enrich zinc and transform inorganic zinc into organic zinc}

Zinc is an essential trace element for human body, which can promote the growth and development of human body and enhance the immune function of human body(Jia et al.,2004). Zinc deficiency can lead to the decrease of lymphocytes and the irrecoverable damage of lymphatic system. However, nearly one third of the world's population is facing health problems caused by zinc deficiency. Zinc in normal diet can not meet the normal needs of human body. In order to ensure the health of human body and prevent related diseases, adequate zinc intake should be provided. The sources of zinc include inorganic zinc and organic zinc. Inorganic zinc is not easy to be absorbed by the body, and excessive intake will produce toxicity. Biological organic zinc has the advantages of high absorption and utilization, safety and non-toxic, so the development of bio organic zinc health products is a safe and effective way to provide zinc source for the body. In order to transform zinc into organic zinc, it is necessary to find suitable zinc enrichment and transformation carriers. The results showed that Flammulina velutipes was an effective carrier for zinc enrichment and transformation (Liu et al.,2014). Our study found that Dendrobium also has the ability to enrich and transform zinc. Zinc can be distributed in different parts of Dendrobium and form zinc polysaccharide with Dendrobium polysaccharides, which provides a new way for zinc enrichment in plants and a new method for obtaining organic zinc from biological sources.

Dendrobium nobile is a kind of precious Chinese herbal medicine, which is traditionally used to nourish the body. Existing studies have shown that Dendrobium nobile has a variety of biological activities, including enhancing immunity. And Dendrobium polysaccharide is the main active component of Dendrobium nobile to enhance immunity. The data show that zinc plays an important role in maintaining the structure and function of the central immune organs (thymus, supraluminal SAC) and peripheral immune organs (lymph nodes, spleen, tonsil). Therefore, the zinc polysaccharide synthesized by zinc and Dendrobium polysaccharide can not only convert inorganic zinc into organic zinc, improve the absorption and utilization rate of zinc, but also greatly promote the enhancement of human immunity.

Therefore, a new plant Dendrobium nobile, which can enrich and transform zinc, has been found in the experiment. At the same time, Dendrobium polysaccharide, a new carrier for the transformation of inorganic zinc into organic zinc, has also been found.

\subsection{Dendrobiumnobile can reduce the damage of zinc stress to plants by chelating zinc with polysaccharide in vivo}

Root is an important organ for plants to absorb water and mineral nutrients, and it is also an important part of soil heavy metal stress. We found that the zinc content in the root of Dendrobium nobile was significantly higher than that in the stem. For example, in the high concentration group $(2000 \mu \mathrm{mol} / \mathrm{L})$, the zinc content in the root was 6.3 times higher than that in the stem.

Heavy metal stress has a certain effect on plant growth. Reactive oxygen species (ROS) produced by plant cells under heavy metal stress can cause oxidative damage. In response to stress, plants produce antioxidants to resist ROS damage to cells. At the same time, plant cells will actively accumulate some soluble substances, 
such as soluble protein and soluble sugar, to reduce the intracellular osmotic potential, so as to ensure the normal water supply under heavy metal stress and maintain the normal physiological function of cells (Zhang et al., 2011). In addition, heavy metal chelation is also an important way for plants to alleviate heavy metal injury. For example, phytochelatins (PC) (Gupta et al., 2013) uses a large number of thiol groups in its structure to coordinate with heavy metal ions to form heavy metal PC chelates, which make heavy metal ions lose activity (Rama et al.,2010; Park et al., 2012), thus reducing the toxicity of heavy metals to plants. At present, some studies have found that the formation of PC can be promoted by adding Se, so as to alleviate the stress of heavy metals (Salt et al., 1995; Rana et al.,1996). Intracellular polyphosphate bodies can also chelate heavy metals. Under the stress of heavy metals, the number of polyphosphate bodies increases, and the phosphorus concentration in plants increases, and the increase of phosphorus concentration can reduce the toxicity of heavy metals to plants (Rai et al.,1981).

The results showed that the photosynthesis and carbohydrate synthesis of Dendrobium nobile increased significantly under the influence of zinc stress, and the biosynthesis of polysaccharide increased. The polysaccharide can combine with zinc well to form polysaccharide zinc chelate, which makes zinc ion lose its activity. This chelate has no toxicity to plants, and the polysaccharide-zinc chelate is transported through the vacuole membrane to be stored in the vacuole under the action of ATP, so as to reduce the damage to Dendrobium nobile and protect it (Fig. 7).

\section{Fig.7}

\section{Conclusion}

The results of this study indicate that $\mathrm{Zn}^{2+}$ had an obvious effect on the physiology and accumulation of medicinal components of Dendrobium nobile. Low concentration $\mathrm{Zn}^{2+}(<400 \mu \mathrm{mol} / \mathrm{L})$ can promote the photosynthesis of Dendrobium nobile, increase the net photosynthetic rate and transpiration rate, increase the stomatal conductance and the content of chlorophyll A and chlorophyll $\mathrm{B}$, reduce the intercellular $\mathrm{CO}_{2}$ concentration and water use efficiency. At the same time, when the concentration of zinc was $200 \mu \mathrm{mol} / \mathrm{L}$ and keep it for 21 days, the stimulation from zinc on Dendrobium nobile could promote the synthesis of antioxidant enzyme SOD, so as to eliminate the free radicals produced by stress. Another finding was that low concentration $\mathrm{Zn}^{2+}(<400 \mu \mathrm{mol} / \mathrm{L})$ can increase the activity of CAT, APX and ASA. However, the maximum value of GSH appeared when the zinc concentration was $800 \mu \mathrm{mol} / \mathrm{L}$. When the concentration of zinc was $400 \mu \mathrm{mol} / \mathrm{L}$, the content of polysaccharide reached the maximum on the 7 th day, the content of polyphenols reached the maximum on the 14th day, but the content of flavonoids reached the maximum on the 21th day. In addition, when the concentration of external zinc treatment reached $800 \mu \mathrm{mol} / \mathrm{L}$, the content of zinc-polysaccharide in the stem of Dendrobium nobile reached the maximum on the 7th days, which indicated that a certain amount of external zinc could promote the synthesis of zinc polysaccharide and promote the transformation of inorganic zinc into organic zinc in Dendrobium nobile. This experiment also found that Dendrobium nobile can transform inorganic zinc into organic zinc, which is stored in the body in the form of zinc-polysaccharide, which greatly improves the medicinal value of Dendrobium nobile, and provides the theoretical basis for research and development of drugs and functional food of Dendrobium nobile. Meanwhile, the polysaccharide can combine with zinc well to form polysaccharide zinc chelate, which makes zinc ion lose its activity, and the polysaccharide-zinc chelate is transported to the vacuole under the action of ATP, so as to reduce the damage to Dendrobium nobile and protect it.

\section{Acknowledgement}

This study was supported by the National Natural Science Foundation of China (31700302).

\section{References}

Altair, B.S., Kristi, A. K., Marcelo, E. R., George, E. B., Jeferson, A. B., Ana, C.A S., Marcos, A. B.,2018. Hair in Parkinson's disease patients exhibits differences in Calcium, Iron and Zinc concentrations measured by flame atomic absorption spectrometry-FAAS, J. Trace Elem. Med. Bio,. 47, 134-139.

Asghar, T., Jamil,Y., Iqbal,M., Haq,Z.U., Abbas,M.,2016. Laser light and magnetic field stimulation effect 
on biochemical, enzymes activities and chlorophyll contents in soybean seeds and seedlings during early growth stages, J. Photoch. Photobio. B, 165, 283-290.

Berni,R., Luyckx,M., Xu,X., Legay,S., Sergeant,K., Hausman,J.F., Lutts,S., Cai,G., Guerriero G.,2019. Reactive oxygen species and heavy metal stress in plants: Impact on the cell wall and secondary metabolism, Environ. Exp. Bot., 161, 98-106.

Carolina, W., Ribeiro, Ana, Paula, K., Julio, A. G., Douglas, J.M., Fabricio, E.L., Carvalho, R.H.V. ,Sousa, A.C., Felipe, K., Teixeira, J.A.G., Silveira, M.M.,2017. Rice peroxisomal ascorbate peroxidase knockdown affects ROS signaling and triggers early leaf senescence, Plant Sci., 263, 55-65.

Chen,L.W., Yang,S.J., Huang,Y., Zhang,B.G., Kang,F.X., Ding, D., Cai,T.M.,2019. Degradation of antibiotics in multi-component systems with novel ternary AgBr/Ag3PO4@natural hematite heterojunction photocatalyst under simulated solar light, J. Hazard. Mater., 371, 566-575.

Fan,Y.J., Yu,Q.S., Wang, G., Tan,J.W., Liu, S., Pu,S.R., Chen,W.C., Xie, P., Zhang,Y.X., Zhang,J., Liao,Y.X., Luo,A.X.,2020. Effects of non-thermal plasma treatment on the polysaccharide from Dendrobium nobile Lindl. And its immune activities in vitro, Int. J. Biol. Macromol., 153, 942-950.

Gao,J.Q., Liu,L., Ma,N., Yang,Jiao., Dong,Z., Zhang,J.S., Zhang,J.L., Cai M.,2020. Effect of ammonia stress on carbon metabolism in tolerant aquatic plant-Myriophyllum aquaticum,Environ. Pollut., 263, 114412.

Gupta, D. K.,Vandenhove, H.,Inouhe, M.,2013.Role of phytochelatins in heavy metal stress and detoxification mechanisms in plants. Heavy Metal Stress in Plants,1 (1),73-94.https://doi.org/10.1007/978-3-642-38469-1_4

Jia, L., Yu, K.X., Yao, L.T., Wen, F.J.,2004. Analysis of Organized Degree and Content of Amino Acid in the Zn-accumulation Mycelia of Cordyceps sinensis. Food and Fementation industries, 30(11),94-98. (In Chinese)

Jin, L., Gao, M.J., Duan, X.H., Guo, X.R.,2015. Characteristics of zinc accumulation. in different parts of Catharanthus roseus under Zinc Stress regulated by exogenous Ethrel . Plant research, 35 (01),150-153. (In Chinese)

Jin, L., Gao, M.J., Duan, X.H., Guo, X.R.,2015. Zn Stress Changchun Spend Different Parts of Zn Accumulation by Exogenous Ethephon Regulation. Bulletin of Botanical Research, 35(1): 150 -153. DOI:10.7525/j.issn.1673-5102.2015.01.023

Kunpatee, K., Traipop, S., Chailapakul,O., Chuanuwatanakul, S.,2020. Simultaneous. determination of ascorbic acid, dopamine, and uric acid using graphene quantum dots/ionic liquid modified screen-printed carbon electrode, Sensor Actuat. B- Chem, 314,128059.

Li, Y.Q., Kong, D.X., Fu,Y., Sussman, M.R., Wu Hong.,2020. The effect of. developmental and environmental factors on secondary metabolites in medicinal plants, Plant Physiol. Bioch., 148, 80-89.

Li, C., Huang,Q., Xiao,J., Fu,Xi., You,L., Liu,R.H.,2016. Preparation of Prunella. vulgaris polysaccharidezinc complex and its antiproliferative activity in HepG2 cells, Int. J. Biol. Macromol., 91, 671-679.

Liao, W.Z., Lu, Y.J, Fu, J.N, Ning, Z.X, Yang, J.G, Ren, J.Y.,2015. Preparation and. Characterization of Dictyophora indusiata Polysaccharide-Zinc Complex and Its Augmented Antiproliferative Activity on Human Cancer Cells. J. Agr. Food. Chem., 63(29), 6525-6534.

Liu, F., Chen, G.T., Hu, Q.H., Zhao, S.W., Zhao, L.Y.,2014. Separation, Purification and Structure Characteristics of Zn-Binding Polysaccharides from Flammulina velutip. Food Science. 35(5),1-7. (In Chinese)

Liu,H., Jiang,W.B., Cao,J.K., Li,Y.C.,2019. Changes in Extractable and Non-extractable Polyphenols and Their Antioxidant Properties during Fruit On-tree Ripening in Five Peach Cultivars, Hortic. Plant J., 5( 4), 137-144. 
Luo, A., and Fan, Y.J,2011. In vitro Antioxidant of a Water-Soluble Polysaccharide from Dendrobium fimhriatum Hook.var.oculatum Hook. Int. J. Mol. Sci. 12, 4068-4079.

Luo, A.X., He, X.J., Zhou, S.D., Fan, Y.J., Luo, A.X, Chun, Z.,2010. Purification, composition analysis and antioxidant activity of the polysaccharides from Dendrobium nobile Lindl. Carbohyd Polym. 79,1014-1019.

Milosevic, N , Slusarenko, A. J.,1996. Active oxygen metabolism and lignification in the hypersensitive response in bean. Physiol. Mol. Plant P., 49(3),143-158.

Nagalakshmi, N , Prasad, M. N. V., 2001. Responses of glutathione cycle enzymes and glutathione metabolism to copper stress in Scenedesmus bijugatus. Plant Sci., 160(2),0-299.

Nie,X.Q., Chen,Y., Li,W., Lu,Y.L.,2020. Anti-aging properties of Dendrobium nobile Lindl.: From molecular mechanisms to potential treatments, J. Ethnopharmacol., 257,112839

Park, J. Y., Song, W.Y., Donghwi, ko., 2012. The phytochelatin transporters AtABCC1. and AtABCC2 mediate tolerance to cadmium and mercury. Plant J, (69), 278-288.

Park,S.J., Ahn,Y.J.,2016. Multi-walled carbon nanotubes and silver nanoparticles differentially affect seed germination, chlorophyll content, and hydrogen peroxide accumulation in carrot (Daucus carota L.), Biocatal. Agr. Biotechnol., 8,257-262.

Quy, D.D., Artik, E.A., Phuong, L.T., Lien, H.H., Felycia, E.S., Suryadi, I., Yi,H.J.,2014.Effect of extraction solvent on total phenol content, total flavonoid content, and antioxidant activity of Limnophila aromatica, J. Food Drug. Anal., 22(3), 296-302.

Rama, D., Rai, J.P.N., 2010.Phytochelatins: peptides involved in heavy metal detoxification. Appl. Biochem. Biotech., 160, 945-963.

Rana, S. V.,1996. Protective effects of GSH, vitamin E, and selenium on lipid peroxidation in cadmium-fed rats. Biol. Trace Elem. Res., 51,161-168.

Rai, L.C., Gaur, J.P., Kumar, H.D.,1981. Protective effects of certain environmental factors on the toxicity of Zn, merecury and methylmercury to chlorella vulgaris. Environ Res, 25,250-259.

Salt, D. E., Prince, R .C., Pickering, I. J., 1995. Mechanisms of cadmium mobility and accumulation in Indian mustard. Plant Physiol., 109: 1427-1443.

Wang,J.H., Luo,J.P., Zha, X.Q., Feng, B.J.,2010. Comparison of antitumor activities of different polysaccharide fractions from the stems of Dendrobium nobile Lindl, Carbohyd. Polym., 79, 1:114-118

Wang,L.Q., Wang,C.Q., Gao,X., Xu,N., Lin, L., Zhao,H.J., Jia,S.H., Jia, L.,2015. Purification, characterization and anti-aging capacity of mycelia zinc polysaccharide by Lentinus edodes SD-08. BMC Complem. Altern. M., 15(1):111-131.

Wang,P.P., Huang,Q., Chen,C., You,L.J., Liu,R.H., Luo,Z.G., Zhao,M.M., Fu, X.,2019.The chemical structure and biological activities of a novel polysaccharide obtained from Fructus Mori and its zinc derivative, J. Funct. Foods, 54,64-73.

Zhang, J. T.,Xu, M.,Han, K.,2011. Effect of salt stress on plant nutrition and physiology of tamato seedings.Acta Agriculturae Boreali-occidentali Sinica, 20 (2) ,128-133. DOI:10.1007/s10499-007-9164-4.

Zhang, J., Xu, Z.Q., Huang, H., Tian, J.M., Zhang, G.D. 2020. Characteristics and Speciation Analysis of Heavy Metals in Soils Around a Phosphate Mining Area in Mabian,Sichuan. Sichuan Environment, 39(2):915. DOI: 10. 14034 /j. cnki. schj. 2020. 02. 002.

Zhang,M., Zhao,H., Shen,Y., Wang,Y., Zhao,Z.M., Zhang,Y.,2020. Preparation, characterization and antioxidant activity evaluation in vitro of Fritillaria ussuriensis polysaccharide-zinc complex, Int. J. Biol. Macromol., 146, 462-474. 
Zheng, L.,Liu, M.,Zhai, G.Y.,Ma, Z.,Wang, L.Q.,Jia, L.2015. Antioxidant and anti-ageing activities of mycelia zinc polysaccharide from Pholiota nameko SW-03. J. Food Agric., 95(15). 3117-3126. DOI:10.1002/jsfa.7048

Tables

Table 1 Effect of WUE of Dendrobium nobile leaves under different Zn treatment

\begin{tabular}{llll}
\hline Unit $\left(\mu \mathrm{mol} \cdot \mathrm{mol}^{-1}\right)$ & $7 \mathrm{~d}$ & $14 \mathrm{~d}$ & $21 \mathrm{~d}$ \\
\hline $\mathrm{ck}$ & $16.94 \pm 2.34 \mathrm{ab}$ & $19.73 \pm 2.60 \mathrm{a}$ & $15.83 \pm 3.82 \mathrm{a}$ \\
T1 & $21.28 \pm 3.45 \mathrm{a}$ & $13.87 \pm 0.45 \mathrm{ab}$ & $10.71 \pm 1.77 \mathrm{ab}$ \\
T2 & $8.64 \pm 3.00 \mathrm{~b}$ & $8.32 \pm 2.11 \mathrm{c}$ & $6.78 \pm 0.24 \mathrm{bc}$ \\
T3 & $14.98 \pm 4.33 \mathrm{ab}$ & $4.36 \pm 1.46 \mathrm{c}$ & $4.24 \pm 1.74 \mathrm{~cd}$ \\
T4 & $5.34 \pm 1.57 \mathrm{~b}$ & $3.33 \pm 1.21 \mathrm{c}$ & $3.07 \pm 0.94 \mathrm{~cd}$ \\
T5 & $10.03 \pm 2.02 \mathrm{ab}$ & $4.11 \pm 1.18 \mathrm{c}$ & $3.83 \pm 0.16 \mathrm{~cd}$ \\
T6 & $7.95 \pm 2.07 \mathrm{~b}$ & $2.09 \pm 0.08 \mathrm{c}$ & $-0.17 \pm 0.01 \mathrm{~d}$ \\
T7 & $8.11 \pm 2.17 \mathrm{~b}$ & $1.32 \pm 0.34 \mathrm{c}$ & $-7.63 \pm 0.78 \mathrm{e}$ \\
\hline
\end{tabular}

Note: Data are means $\pm S E$ in the figures. Different letters indicate significant differences among the treatments $(P<0.05)$. CK, T1, T2, T3, T4, T5, T6 and T7 indicate that corresponding Zinc concentration is 0 , $50,100,200,400,800,1000$ and $2000 \mu \mathrm{mol} / \mathrm{L}$.

Table 2 Effect of chlorophyll content of Dendrobium nobile leaves under different $\mathrm{Zn}$ treatment

\begin{tabular}{lllllllll}
\hline Chl & Time & ck & T1 & T2 & T3 & T4 & T5 & T6 \\
\hline & $7 \mathrm{~d}$ & $0.72 \pm 0.03 \mathrm{bc}$ & $0.72 \pm 0.07 \mathrm{bc}$ & $0.76 \pm 0.02 \mathrm{abc}$ & $0.78 \pm 0.01 \mathrm{abc}$ & $0.6 \pm 0.01 \mathrm{a}$ & $0.80 \pm 0.04 \mathrm{ab}$ & $0.70 \pm 0.02 \mathrm{l}$ \\
Chl.A & $14 \mathrm{~d}$ & $0.81 \pm 0.01 \mathrm{~cd}$ & $0.20 \pm 0.05 \mathrm{~cd}$ & $0.82 \pm 0.08 \mathrm{~cd}$ & $0.91 \pm 0.01 \mathrm{bc}$ & $1.11 \pm 0.08 \mathrm{a}$ & $1.00 \pm 0.07 \mathrm{ab}$ & $0.83 \pm 0.04 \mathrm{c}$ \\
mg.g-1 FW & $21 \mathrm{~d}$ & $0.85 \pm 0.01 \mathrm{e}$ & $0.86 \pm 0.02 \mathrm{de}$ & $0.87 \pm 0.02 \mathrm{cde}$ & $0.92 \pm 0.01 \mathrm{c}$ & $1.15 \pm 0.01 \mathrm{a}$ & $1.08 \pm 0.04 \mathrm{~b}$ & $0.92 \pm 0.01 \mathrm{c}$ \\
& $7 \mathrm{~d}$ & $0.29 \pm 0.01 \mathrm{~b}$ & $0.34 \pm 0.06 \mathrm{ab}$ & $0.37 \pm 0.01 \mathrm{a}$ & $0.39 \pm 0.01 \mathrm{a}$ & $0.41 \pm 0.02 \mathrm{a}$ & $0.39 \pm 0.01 \mathrm{a}$ & $0.30 \pm 0.01 \mathrm{l}$ \\
Chl.B & $14 \mathrm{~d}$ & $0.35 \pm 0.01 \mathrm{c}$ & $0.37 \pm 0.03 \mathrm{bc}$ & $0.38 \pm 0.05 \mathrm{bc}$ & $0.42 \pm 0.01 \mathrm{abc}$ & $0.50 \pm 0.03 \mathrm{a}$ & $0.46 \pm 0.03 \mathrm{ab}$ & $0.39 \pm 0.011$ \\
mg.g-1 FW & $21 \mathrm{~d}$ & $0.36 \pm 0.01 \mathrm{e}$ & $0.37 \pm 0.02 \mathrm{e}$ & $0.39 \pm 0.02 \mathrm{e}$ & $0.42 \pm 0.01 \mathrm{~d}$ & $0.54 \pm 0.01 \mathrm{a}$ & $0.50 \pm 0.01 \mathrm{~b}$ & $0.46 \pm 0.01 \mathrm{c}$ \\
\hline
\end{tabular}

Note: Data are means $\pm S E$ in the figures. Different letters indicate significant differences among the treatments $(P<0.05)$. CK, T1, T2, T3, T4, T5, T6 and T7 indicate that corresponding Zinc concentration is 0 , $50,100,200,400,800,1000$ and $2000 \mu \mathrm{mol} / \mathrm{L}$.

Table 3 Effect of SOD and CAT activities of Dendrobium nobileleaves under different Zn treatment

\begin{tabular}{llllllll}
\hline & Time & $\mathrm{ck}$ & T1 & T2 & T3 & T4 & T5 \\
\hline & $7 \mathrm{~d}$ & $379.39 \pm 3.99 \mathrm{bc}$ & $402.25 \pm 17.97 \mathrm{bc}$ & $476.33 \pm 4.51 \mathrm{a}$ & $491.18 \pm 25.61 \mathrm{a}$ & $523.46 \pm 12.70 \mathrm{a}$ & $412.62 \pm 12$ \\
$\mathrm{SOD}\left(\mathrm{U} \cdot \mathrm{g}^{-1} \mathrm{FW}\right)$ & $14 \mathrm{~d}$ & $421.16 \pm 7.20 \mathrm{~b}$ & $427.47 \pm 5.41 \mathrm{~b}$ & $521.93 \pm 5.41 \mathrm{a}$ & $524.47 \pm 3.46 \mathrm{a}$ & $527.80 \pm 8.40 \mathrm{a}$ & $459.64 \pm 8$. \\
& $21 \mathrm{~d}$ & $438.17 \pm 9.05 \mathrm{~b}$ & $440.72 \pm 15.70 \mathrm{~b}$ & $538.02 \pm 16.92 \mathrm{a}$ & $550.00 \pm 4.60 \mathrm{a}$ & $518.99 \pm 10.35 \mathrm{a}$ & $450.84 \pm 23$ \\
& $7 \mathrm{~d}$ & $55.56 \pm 8.68 \mathrm{f}$ & $72.22 \pm 4.01 \mathrm{f}$ & $112.22 \pm 7.29 \mathrm{e}$ & $157.78 \pm 4.45 \mathrm{~d}$ & $176.67 \pm 5.77 \mathrm{~cd}$ & $191.11 \pm 8$. \\
$\mathrm{CAT}\left(\mathrm{U} \cdot \mathrm{g}^{-1} \mathrm{FW}\right)$ & $14 \mathrm{~d}$ & $57.78 \pm 8.68 \mathrm{e}$ & $77.78 \pm 8.61 \mathrm{e}$ & $115.56 \pm 5.88 \mathrm{~d}$ & $156.66 \pm 14.53 \mathrm{c}$ & $180.00 \pm 9.62 \mathrm{bc}$ & $204.45 \pm 4$. \\
& $21 \mathrm{~d}$ & $63.67 \pm 7.41 \mathrm{a}$ & $107.78 \pm 11.76 \mathrm{~d}$ & $120.00 \pm 6.94 \mathrm{~d}$ & $176.66 \pm 0.82 \mathrm{c}$ & $184.44 \pm 8.01 \mathrm{bc}$ & $205.56 \pm 14$ \\
\hline
\end{tabular}

Note: Data are means $\pm S E$ in the figures. Different letters indicate significant differences among the treatments $(P<0.05)$. CK, T1, T2, T3, T4, T5, T6 and T7 indicate that corresponding Zinc concentration is 0 , $50,100,200,400,800,1000$ and $2000 \mu \mathrm{mol} / \mathrm{L}$. 


\section{Hosted file}

Figure captions.pdf available at https://authorea.com/users/366222/articles/485999-zincaffects-physiology-and-biosynthesis-of-medicinal-components-in-dendrobium-nobile-lindl

\section{Hosted file}

Figures.pdf available at https://authorea.com/users/366222/articles/485999-zinc-affectsphysiology-and-biosynthesis-of-medicinal-components-in-dendrobium-nobile-lindl 